\title{
LA POETICA EXPLOSIVA DE ROBERTO JUARROZ
}

\author{
POR \\ THORPE RUNNING \\ St. John's University
}

La poesía de Roberto Juarroz se caracteriza por una exploración de lo que es la poesía misma, enfocándose en su lenguaje y sus límites. Esta preocupación lo asemeja a otros poetas contemporáneos - notables experimentadores como José Lezama Lima, Enrique Molina, Jaime Sabines, Alberto Girri, entre otros- que inician la nueva vanguardia, o antivanguardia, de la poesía en la América Latina. Es éste el juicio de Octavio Paz en una breve nota («unas cuantas noticias mínimas») al final de su libro Los hijos del limo sobre las evoluciones más recientes de la poesía moderna. Como valoración general es muy sagaz, porque aunque esos poetas cubren toda la gama desde el surrealismo hasta la poesía narrativa y aforística, sus exploraciones no se centran en la estética, sino en «la zona del lenguaje» 1 .

Nadie, sin embargo, ha emprendido sus indagaciones con una visión más resuelta ni con una autolimitación más rigurosa que Juarroz. La suya es una poesía de introspección e introversión que empieza preguntándose sobre los límites de la poesía y de su lenguaje, y que llega a un potente concepto: el de una palabra poética explosiva. Juzgada por sus propios méritos, la Poesía vertical que ha establecido - todos sus libros llevan ese mismo título- es una obra de gran importancia; pero cobran aún más interés cuando se advierte que su temática prefigura la preocupación ahora tan actual de «desconstruir» la poesía y su lenguaje, tal como la expresa Jacques Derrida. La poesía de Juarroz también refuerza el formidable ataque de Maurice Blanchot contra los límites de la expresión poética. Al ser un excelente muestrario de esas teorías, el esfuerzo de Juarroz representa una inversión completa de la base de la poesía moderna.

\footnotetext{
${ }^{1}$ Octavio Paz, Los hijos del limo (Barcelona: Seix Barral, 1974), pp. 106-109.
} 
Parecería a primera vista que una poesía preocupada por sus límites y que se vuelve hacia adentro no llevaría a ningún desarrollo innovador: se creería que esa orientación produciría una falta de movimiento. Pero empezando con la primera Poesía vertical, de 1958, vemos que un sondeo de las honduras de la poesía misma lleva a nuevos comienzos.

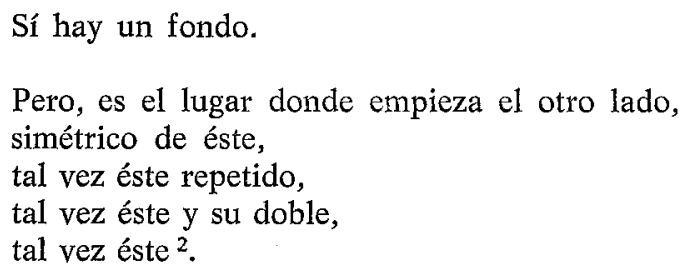

Esta es una síntesis de la búsqueda de una base para la poesía que se lleva a cabo a través de los seis volúmenes de Juarroz. Esta búsqueda depende de dos elementos cruciales e interdependientes: la búsqueda de un centro («es el lugar donde empieza el otro lado»), que está expresada explícitamente en muchos de sus poemas, y la necesidad de la repetición, un elemento constante en la poesía de Juarroz. Dice Guillermo Sucre que «el suyo es un discurrir que se repite incesantemente» ${ }^{3}$, y ese discurrir repetitivo está indicado en este poema por las palabras «repetido», «doble», «simétrico» y la anáfora de «tal vez éste». Estas dos constantes determinan la investigación del problema de la estructura, que es el elemento más crucial de la temática de Juarroz, investigación que precede a las consideraciones semejantes, pero más filosóficas, de Derrida. Como Derrida señala explícitamente, sin embargo, esta investigación no es para él una cuestión "estructuralista», sino una nueva manera de mirar el concepto histórico de la «estructura» misma. La clave de este concepto es, como también lo es en la poesía de Juarroz, el proceso de la repetición; y un repaso de las reflexiones de Derrida sobre «La structure, le signe et le jeu» ayudará a entender las exploraciones similares de Juarroz.

Peut-être s'est-il produit dans l'histoire du concept de structure quelque chose qu'on pourrait appeler un «événement» si ce mot n'impor-

${ }^{2}$ Roberto Juarroz, Poesía vertical (1958-1975) (Caracas: Monte Avila, 1975), p. 36 .

${ }^{3}$ Guillermo Sucre, La máscara, la transparencia (Caracas: Monte Avila, 1975), p. 237. En la ocasión de una lectura pública que dio en la Universidad de Minnesota (octubre de 1981), el poeta W. S. Merwin, traductor de Juarroz al inglés, dijo que, para su gusto, "Juarroz es demasiado repetitivo a veces». 
tait avec lui une charge de sens que l'exigence structurale —ou structuraliste- a justement pour fonction de réduire ou de suspecter. Disons néanmoins un "événement» et prenons ce mot avec précautions entre des guillemets. Quel serait donc cet événement? Il aurait la forme extérieure d'une rupture et d'un redoublement ${ }^{4}$.

Este redoublement es el resultado de una autorreflexión, dentro de la obra, sobre su propia «estructuralidad», como lo ilustra el poema 33 de Juarroz («es el lugar donde empieza el otro lado, simétrico de éste»), y como Derrida aclara al precisar lo que entiende por «evento»:

L'événement de rupture, la disruption à laquelle je faisais allusion en commençant, se serait peut-être produite au moment où la structuralité de la structure a dû commencer à être pensée, c'est-à-dire répétée... (p. 411).

Para Juarroz como para Derrida, el elemento central de «la estructuralidad de la estructura», y, por extensión, de la esencial repetición, es la búsqueda del "centro». En efecto, la inseguridad o la ambigüedad del centro es lo que hace que la repetición sea tan necesaria y, a la vez, tan valiosa. Lo importante de esta búsqueda es algo que Derrida explica, con más detalle, en el mismo ensayo.

On a donc toujours pensé que le centre, qui par définition est unique, constituait, dans une structure, cela mềne qui, commandant la structure, échappe à la structuralité. C'est pourquoi, pour une pensée classique de la structure, le centre peut être dit, paradoxalement, dans la structure et hors de la structure (p. 410).

Juarroz se adelanta a esa misma observación cuando no vacila en declarar, en su poema 16 de la segunda Poesía vertical (1963), lo difícil que es esta búsqueda de un centro.

El centro no es un punto.

Si lo fuera, resultaría fácil acertarlo (p. 73).

Casi como si quisiera mostrar que está hablando del mismo centro que en ese poema le preocupa a Juarroz, Derrida va un poco más allá de

${ }^{4}$ Jacques Derrida, L'écriture et la différence (Paris: Éditions du Seuil, 1967), p. 409. El emparejamiento de pensamientos teóricos en prosa con una obra poética, con el fin de explicar la poesía, ha sido puesto en práctica exitosamente por María del Carmen Bobes Naves en Gramática de "Cántico" (Barcelona: Ediciones Planeta, 1975), p. 166. 
ese concepto de «el centro no es un punto» cuando dice que «le centre n'est pas le centre». Lo que quiere decir Derrida a través de esas declaraciones es que con cada nueva estructura (una palabra, un poema, lo que sea) hay un nuevo centro («une série de substitutions de centre à centre, un enchaînement de déterminations du centre», p. 410). Cada palabra o símbolo, al repetirse, pertenece luego a una estructura cambiada que tiene un nuevo - o desplazado - centro, y a causa de esa nueva base llega a ser un elemento diferente (aproximadamente el proceso que Derrida llama «différence»). Y con la adición de cada nueva repetición el centro de la construcción poética entera se desplaza otra vez; todo este proceso forma así una serie de nuevos «centros», mediante las «sustituciones infinitas»; también surgen sentidos nuevos y acrecentados del proceso que Derrida llama «supplémentarité»: el signo que reemplaza el centro desplazado lo suplementa («en supplément») y agrega algo ( ajoute quelque chose»). Es la capacidad del centro de estar simultáneamente dentro y "fuera de la estructura» lo que permite este movimiento y esta repetición infinita de la estructura. El centro se vuelve, para citar a Maurice Blanchot, «la concentration de l'ambiguitté», y la «palabra poética» que así resulta llega a ser una «palabra neutral» que Blanchot describe de la siguiente manera:

Cette parole est essentiellement errante, étant toujours hors d'ellemême. Elle désigne le dehors infiniment distendu qui tient lieu de l'intimité de la parole. Elle ressemble à l'écho, quand l'écho ne dit pas seulement tout haut ce qui est d'abord murmuré, mais se confond avec l'immensité chuchotante, est le silence devenu l'espace retentissant, le dehors de toute parole. Seulement, ici, le dehors est vide, et l'écho répète par avance, "prophétique dans l'absence de temps» ${ }^{5}$.

El centro cambiante o ambiguo reaparece constantemente en la poesía de Juarroz y lo lleva a un concepto del «signo poético» que es casi un «eco» perfecto del de Blanchot. Propone su propia versión de la idea de hors de, esencial en las teorías de Blanchot y Derrida, en esta línea del poema 6 (1965):

Hasta el tronco central cae afuera del bosque (p. 123).

Se encuentran en sus poemas 52 (de 1963) y 8 (de 1965) explicaciones gráficas del proceso de repetición estructural en —o alrededor deun centro cambiante:

\footnotetext{
${ }^{5}$ Maurice Blanchot, L'Espace Littéraire (Paris: Gallimard, 1955), p. 52.
} 


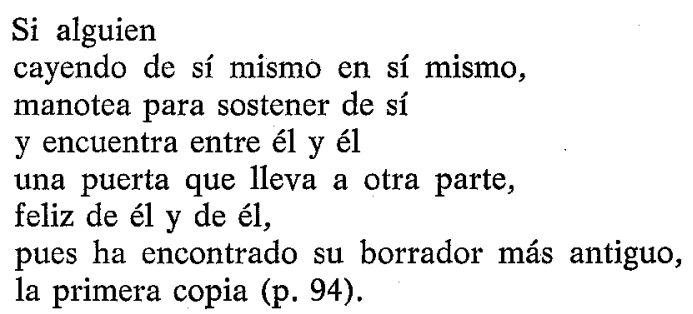

Aunque expresado en términos personales, refiriéndose a «alguien», está claro que el poema trata de los actos de redoublement («cayendo de sí mismo en sí mismo») y de repetición por medio de elementos sencillos («entre él y él», «de él y de él») cuya capacidad de dividirse o duplicarse y luego de repetirse (la rupture y el redoublement de Derrida) indica que hay un centro ambiguo que pone a disposición de ese alguien la «puerta que lleva a otra parte». Esta «otra parte» es el comienzo del proceso artístico, «la primera copia», que, sin embargo, es solamente el «borrador más antiguo». Esto último nos da una imagen muy borgiana de la obra de arte como palimpsesto: manuscrito compuesto por muchos niveles de textos, palabras por encima de otras palabras desplazadas. La metáfora es muy apta para las descripciones que hace Juarroz del proceso poético, al que ve como un acrecentamiento continuo mediante repeticiones de palabras. En el poema 8 vemos otra versión de este mismo procedimiento.

Hay instantes en que el mundo se contrae, se aprieta en torno a un punto vivo, para defender allí una culminación de la densidad, una flor de raíz, una letra inicial o final (p. 146).

Obviamente, el «mundo que se contrae» en este poema es otra manera de exponer (otro redoublement si se quiere) el caer «de sí mismo en sí mismo» del poema 52, y el "punto vivo» de este poema es otra descripción del «centro que no es el centro». A medida que se agregan más textos al continuo palimpsesto de Juarroz, la repetición logra una «culminación de densidad», que tiene cierta semejanza con el concepto de «supplémentarité» de Derrida; lleva, como las dos últimas líneas lo indican, a una etapa de creación, aunque ésta sea algo incierta. Es importante notar aquí que estos textos nos dejan con una idea indefinida 
con respecto a comienzos y terminaciones (borrador, flor/raíz, inicial o final), puesto que Juarroz ya se está rebelando contra las limitaciones, algo que otro poema indica claramente:

E1 signo no es algo que ocurre entre sus extremos sino la anulación de esos extremos.

Lo que ocurre entre ellos sucede en verdad afuera.

Promontorio con forma de valle

donde el ojo comprende su sustancia (p. 83).

Aquí vemos cómo Juarroz coincide estrechamente con el concepto de Blanchot de que la palabra "es esencialmente errante, estando siempre fuera de sí misma». La primera línea de este poema da una versión más explícita de la separabilidad o la «ruptura» del signo visto antes en el «entre él y él» del poema 52. Los límites («los extremos») que son los resultados de esa abertura del signo pueden ser borrados ( «la anulación de esos extremos») por el concepto mismo del signo que «sucede afuera», y que está, en las palabras de Blanchot, «siempre fuera de sí mismo». Dada esta aparente liberación de toda limitación, Juarroz, en otro poema, llega a indagar sobre «el límite mismo de lo que puede ser nombrado» (p. 103). Porque las palabras, al menos las que usamos en la comunicación diaria, tienen sus propios significados, lo que les da ciertas limitaciones; este concepto es el tema del poema 45 (1969), como vemos en la primera estrofa:

E1 fruto se rompe

en el límite mismo de la mano.

El fruto quiere ser mano y no fruto,

límite de sí mismo,

corazón enrollado (p. 208).

Este poema continúa con una serie de estrofas que siguen el mismo modelo («el camino se rompe...», "el amor se rompe...», etc.), donde los objetos nombrados, así como las palabras que los representan, se describen como si fueran incapaces de superar las circunstancias de su propia «présence», para usar el término de Derrida.

La experiencia de la restricción se extiende desde la palabra hasta la página escrita, y luego, en el poema 2 , de 1974, hasta todo el proceso creativo. 
Llega un día

en que la mano percibe los límites de la página y siente que las sombras de las letras que escribe saltan del papel.

Detrás de esas sombras, pasa entonces a escribir en los cuerpos repartidos por el mundo, en un brazo extendido, en una copa vacía, en los restos de algo.

Pero llega otro día en que la mano siente que todo cuerpo devora furtiva y precozmente el oscuro alimento de los signos.

Ha llegado para ella el momento de escribir en el aire, de conformarse casi con su gesto. Pero el aire también es insaciable y sus límites son oblicuamente estrechos.

La mano emprende entonces su último cambio: pasa humildemente a escribir sobre ella misma (p. 226).

Muy semejante al poema número 10 de la primera Poesía vertical, que comentamos en otro lugar («hallé un hombre escribiendo en sus huesos») ${ }^{6}$, este poema, escrito unos dieciséis años más tarde, reitera algunos de los elementos del anterior, especialmente «la mano», que aquí escribe en «los cuerpos repartidos por el mundo», en «un brazo extendido» $\mathrm{y}$ en «los restos de algo». $\mathrm{Y}$ al final de este poema vemos casi una repetición del modelo del primer tomo: allí el poeta escribe en su propio hombro mientras que aquí la mano (el poeta) escribe «sobre ella misma». La tercera y la cuarta estrofas agregan algo más, sin embargo: se advierte que las palabras ( «los signos») no tienen ni existencia ni sentido ( $a$ alimento») que se extienda fuera de ellas mismas. La obra literalmente devora, o absorbe -impone límites sobre- «el oscuro alimento» de los signos, una imagen que bien indica la naturaleza incierta

${ }^{6}$ «Roberto Juarroz: Vertical Poetry and Structuralist Perspective», que se publicará en Chasqui: revista de literatura latinoamericana en enero de 1983. 
o cambiante del signo mismo. Su naturaleza efímera se aclara en la cuarta estrofa, donde el poeta se ve reducido a escribir en el aire y su arte se reduce al gesto de escribir. Debido a la momentaneidad del signo evocado de esa manera, y al hecho de que aun el aire, como lo vemos aquí, tiene límites que son «oblicuamente estrechos», el resultado -que tendrá mucha importancia para nuestro comentario- es que el signo, descrito así, no puede transmitirse.

Todo lector que tenga alguna familiaridad con la definición lingüística del «signo» verá en este punto que este poema está refutando el concepto tradicional del signo como significante-significado (el Signifiant/signifié de Saussure). Tenemos en este texto un poeta («la mano»), el destinateur que evoca sus significantes («las letras», «los signos»), pero éstos se evaporan dentro de sus propias limitaciones; no hay ni significados ni un destinatario (destinataire) para recibir o «descifrar» su mensaje.

Aquí vemos, específicamente, que Poesía vertical se ha venido desarrollando en una dirección completamente opuesta al concepto generalizado sobre la poesía moderna. Un elemento crucial aquí es que al negar (o al insistir en no admitir) hasta la existencia del signifié, o sea, el signo recibido, estos textos de Juarroz efectivamente hacen que la metáfora sea inconcebible, una conclusión necesaria que la siguiente definición de Derrida aclara:

la métaphore en général, passage d'un étant à un autre, ou d'un signifié à un autre, autorisé par l'initiale soumission et le déplacement analogique de l'être sous l'étant... (Derrida, p. 45).

La resistencia a someterse a sí mismo como poeta -o a someter a sus palabras como signos poéticos- a ese proceso analógico es lo que da a Juarroz, y a su obra, una muy perceptible unicidad. En un estudio excepcionalmente agudo de las relaciones entre «Le poétique et 1'analogique» a través de la tradición occidental, François Rigolot señala una definición de la poesía moderna ya establecida:

Une idée toute faite de la conscience poétique moderne, celle qui établit une adéquation entre l'analogique et le poétique et mesure la réussite d'un poète à sa faculté de trouver des analogies parlantes: le poète grand syntaxier de l'analogie ${ }^{7}$.

${ }^{7}$ François Rigolot, «Le poétique et l'analogique», en T. Todorov et al., Sémantique de la poésie (Paris: Éditions du Seuil, 1979), p. 174. 
La expresión «syntaxier de l'analogie» corresponde perfectamente tanto a los ultraístas que lo preceden como a los surrealistas contemporáneos de Juarroz. Aunque Juarroz rechaza completamente toda la raison d'être de esos movimientos de vanguardia, a veces, como en el poema 18 de 1974, cede a una tentación residual de imitarlos y de «anotar imágenes». En este poema, sin embargo, el ejercicio de apuntar imágenes («voy apuntando imágenes») llega a ser pura futilidad («el cociente furtivo de la sombra/el residuo de un relámpago...», etc.). Lo que resulta de esa serie de imágenes que se reducen a la nada es una ausencia mallarmeana, la página en blanco, que es, paradójicamente, un retorno al comienzo: «voy llegando al comienzo: la palabra sin nadie» (p. 237). Esta es la palabra únicamente como significante (destinateur sin destinataire).

Esa seguridad de haber encontrado un proceso revitalizado continúa en la quinta Poesía vertical (1975), pero en el primero de los poemas Juarroz describe - en primera persona - su actitud, usando un lenguaje irónicamente ambivalente:
He llegado a mis inseguridades definitivas.
Aquí comienza el territorio
donde es posible quemar todos los finales
y crear al propio abismo,
para desaparecer hacia adentro (p. 273).

Describir las «inseguridades» como «definitivas» parece paradoja, pero Juarroz, al contrario, está reiterando su certeza de la indeterminación de la poesía. No tiene base fija, y por eso tampoco tiene límites: situación que deriva de la posibilidad de abrir y duplicar los «signos» de que está hecha la poesía (y que los signos mismos hacen). Anulando, pues, los límites o extremos de esos signos («quemar todos los finales»), el poeta crea «su propio abismo»: una situación creativa infinita dentro de la cual puede desaparecer. Este verbo final subraya tanto la inseguridad mencionada al comienzo de la estrofa como la infinidad que es la hondura poética en la cual se encuentra el yo, o, mejor dicho, donde puede perderse.

$\mathrm{Si}$ quedara alguna duda de que los signos, a los cuales se refiere a través de los seis tomos de Poesía vertical, representan solamente el significante, el siguiente poema del tomo final elimina explícitamente esas dudas: 
Hay mensajes cuyo destino es la pérdida, palabras anteriores o posteriores a su destinatario, imágenes que saltan del otro lado de la visión, signos que apuntan más arriba o más abajo de su blanco, señales sin código, mensajes envueltos por otros mensajes, gestos que chocan contra la pared, un perfume que retrocede sin volver a encontrar su origen, una música que se vuelca sobre sí misma como un caracol definitivamente abandonado.

Pero toda pérdida es el pretexto de un hallazgo.

Los mensajes perdidos

inventan siempre a quien debe encontrarlos (p. 274).

Toda la primera parte de este poema trata de la palabra poética («mensaje», "palabras», «imágenes», «signos», "señales», "gestos», «perfume», "música», «caracol») como si tuviera sólo un aspecto o faceta, como significante sin significado. Aunque sea tedioso repetir la lista de ejemplos que se encuentran en el poema, parece importante subrayar la manera tan específica y explícita con que Juarroz ilustra esta su preocupación principal: después de la pérdida del destino y del destinatario de las primeras dos líneas, hay imágenes que escapan a la vista, signos mal apuntados, señales indescifrables, mensajes sujetados por otros mensajes, gestos sin salida, un perfume evaporado, una música volcada y un caracol abandonado. Pero, según el evangelio de Juarroz, estar sin salida o estar perdido equivale a un encontrarse en definitiva. «El mensaje perdido», o sea, el signo como significante desnudado de su significado, ya tiene el poder de «inventar» o crear, mediante un proceso incesante («siempre») y autónomo, su propio destino y su propio lector.

Las palabras mismas, en efecto, en el poema 31 , sí determinan su propio destino «enseñando» al poeta (el «sujeto» de primera persona en el poema) su «ritmo secreto y solitario»:

El material con que se construyen las palabras

y la argamasa que lo une

me han ido enseñando poco a poco

un ritmo secreto y solitario.

La independencia de las palabras se destaca claramente en la primera línea: las palabras «se construyen» y sus componentes - su material, su argamasa - emprenden la tarea de revelar al poeta el ritmo se- 
creto de la construcción poética. Todo este proceso, claro está, y como Blanchot señala con detalle, se remonta al deseo que expresaba Mallarmé de que las palabras fueran autónomas para que él pudiera luego «céder l'initiative aux mots» ${ }^{8}$. El resultado de esa autoconstrucción es «una música» («he aprendido así que toda construcción es una música»), reminiscente de la «disonancia que canta» del poema 18. Para aceptar esa definición de la palabra poética, Juarroz ha tenido que hacer un sacrificio, un «choix réductif poétique» (Rigolot, 174), como resume el poeta al principio de un poema clave final, el número 40 de 1975 . Esta reducción se caracteriza por un «desbautizo del mundo» mediante un sacrificio de «el nombre de las cosas» (subrayado nuestro); lo cual significa que se abandona el sentido que la relación presunta o aceptada entre significante y significado da a los nombres:

\section{0}

Desbautizar el mundo, sacrificar el nombre de las cosas

para ganar su presencia.

El mundo es un llamado desnudo, una voz y no un nombre, una voz con su propio eco a cuestas.

$Y$ la palabra del hombre es una parte de esa voz, no una señal con el dedo, ni un rótulo de archivo, ni un perfil de diccionario, ni una cédula de identidad sonora, ni un banderín indicativo de la topografía del abismo.

El oficio de la palabra, más allá de la pequeña miseria y la pequeña ternura de designar esto o aquello, es un acto de amor: crear presencia.

El oficio de la palabra es la posibilidad de que el mundo diga al mundo, la posibilidad de que el mundo diga al hombre.

La palabra: ese cuerpo hacia todo.

La palabra: esos ojos abiertos (p. 299).

${ }^{8}$ Maurice Blanchot, La Part du feu (Paris: Gallimard, 1949), pp. 35-48. Blanchot se da cuenta de las contradicciones inherentes a un lenguaje así aislado del hombre, y admite que la literatura de este tipo se vuelve «impostura», algo que Derrida también admite cuando describe la literatura como un «juego». 
Es obvio que este poema es una síntesis y una repetición de los aspectos claves de la poética de Juarroz. Que se trata de una poética basada en la repetición se demuestra en el gran número de redoublements léxicos del poema, cuyo inventario damos aquí: «mundo», «nombre», «presencia», «voz», «palabra», «hombre», «oficio», «posibilidad». La primera estrofa, una vez más, describe el abandono del «nombre de las cosas» (el signo como $\mathrm{S} / \mathrm{s}$ ). El «llamado desnudo» de la segunda estrofa, así como la "voz y no un nombre», indican el destinateur sin destinataire. Conforme a esta idea, cuando el signo emite un «eco». resonante y significativo, esa resonancia sigue siendo parte del signo: no se transmite. Debe notarse que el término que denota que el «eco» pertenece a su propio cuerpo - «a cuestas»- también lleva en sí el aspecto de verticalidad que Juarroz ve en todas las estructuras y palabras infinitamente repetidas y repetibles en su hondura poética: signos o resonancias de signos unos encima de otros. Los términos «eco» y «a cuestas» son paralelos casi exactos de los que usa Maurice Blanchot tanto en la cita anterior como en este ejemplo, donde describe la escritura como un lenguaje infinito e incesante:

Êcrire, c'est se faire l'écho de ce qui ne peut cesser de parler... (L'Espace Littéraire, p. 18).

Como reitera la tercera estrofa del poema, la palabra descrita así no contiene un sentido fijo (un significado) que se pueda transmitir: no es «una señal con el dedo», ni «un rótulo de archivo», ni «una cédula de identidad sonora», etc.

En la cuarta estrofa hay un reconocimiento de tipo borgiano - frente a la realidad- - de que la palabra sí designa «esto o aquello». Su verdadera misión, la misión poética, que es también, significativamente, un acto de amor, es la de «crear presencia», que es; esencialmente, lo que Derrida, usando el mismo término, expresa por «la détermination de l'être comme présence à tous les sens de ce mot». (p. 411): «L'être», para Derrida, recordemos, es el término para el significante, en comparación con «l'étant» para el significado. Después de haber rechazado la palabra como Signifiant/signifié en las tres primeras estrofas, es obvio que Juarroz ahora ve una verdadera significancia que se crea a través del ser de la palabra, su presencia como significante: una «explosión del ser», como Juarroz mismo ha llamado el proceso poético en una entrevista con Guillermo Boido ${ }^{9}$. La palabra, concebida de esta manera, tiene una

9. Guillermo Boido, «Entrevista con Roberto Juarroz» (Hispamérica, año VI, núm. 17, 1977), pp. 47-59. 
clara función poética comunicativa («que diga»), que se deriva de su presencia desafiante («su cuerpo hacia todo») y sus posibilidades inherentes de creación («esos ojos abiertos»).

No solamente es este poema una repetición y una síntesis de la poética y el concepto de un lenguaje poético que Juarroz ha venido desarrollando; es también prácticamente una reiteración de la idea que tiene Blanchot del escritor y su lenguaje:

L'écrivain appartient à un langage que personne ne parle, qui ne s'addresse à personne, qui n'a pas de centre, qui ne révèle rien... Là où il est, seul parle l'être -ce qui signifie que la parole ne parle plus, mais est, mais se voue à la pure passivité de l'être (Blanchot, p. 17).

Cuando Juarroz, como Blanchot, se desprende del lenguaje que «habla», y en cambio cuenta con la palabra como «être» (ser) o como significante únicamente, está rechazando la búsqueda de las analogías infinitas basadas en relaciones entre significados, que los poetas de la vanguardia y la "posvanguardia», como hemos observado, consideraban como su razón de ser. Aún más: esos poetas casi no vieron alternativa a la de ser «syntaxiers de l'analogie». Octavio Paz, que se encuentra entre los que consideran que la poesía moderna está hecha de analogías en la tradición de las Correspondances de Baudelaire, dice que, para el poeta moderno, la única alternativa a esa búsqueda analógica ha sido una visión irónica: ver el mundo, y el mundo de la poesía, como grotesco, bizarro, sin sentido y «abismal». Además, Paz dice que para el poeta irónico «la ironía no es una palabra ni un discurso, sino el reverso de la palabra, la no comunicación» ( $\mathrm{Paz}, \mathrm{p}$. 109). Hasta cierto punto estos términos describen a Juarroz y su poesía. Palabras como "hueco», «vacío», «abismo» y «fondo» figuran prominentemente en la lista de palabras repetidas con frecuencia en Poesía vertical. Juarroz, sin embargo, ve el «hueco» como elemento positivo, puesto que es el resultado de una falta de centro fijo para su léxico, lo que le permite acudir al «signo» poético: el «ser», el significante solo, que es precisamente la «palabra de no comunicación» a que se refiere Octavio Paz.

Mientras que los poetas vanguardistas vieron el procedimiento de formar analogías como una búsqueda constante de nuevas combinaciones de términos, todos esos términos estaban determinados y limitados por sus significados, aun cuando polivalentes. (La palabra que usaba el cubista Pierre Reverdy para los dos elementos de que se formaba una analogía - réalités - bien expresaba su esencia determinada.) El proceso mismo de la analogía, como hemos señalado, se basa en la necesidad de 
que las palabras tengan sentidos fijos: «signifiés» o «étants», que el lector debe yuxtaponer en su mente para formar una nueva imagen. Juarroz, en cambio, pasa al signo poético desnudado de su significado y que lleva su «eco a cuestas», creando así una «disonancia que canta». Como Blanchot, ve ese signo como una palabra infinita que, si no «habla» convencionalmente, llega a ser un ser o un signo perfectamente poético que «devient image, devient imaginaire, profondeur parlante» (Blanchot, 18). E1 signo poético que habita esta "hondura hablante» es la base para la poesía de infinita verticalidad, de infinitas resonancias, y es la confirmación de lo que Juarroz afirmaba en su primer libro: «Sí, hay un fondo.» En lugar de la «palabra de no comunicación» de que habla Paz, la palabra poética autoafirmativa de Juarroz lleva en sí la capacidad de producir una «explosión del ser», y así tiene una función comunicativa inmediata y autónoma que no requiere ningún «puente» del lector. Así se logra una poesía ilimitada e inmediatamente eficaz, dotada de lo que Maurice Blanchot llama (p. 26) «la violence éclairante de la communication». 